\title{
THE EVALUATION OF PROGRAM DEATH 1 (PD-1) AND PD-1 LIGAND (PD-L1) EXPRESSIONS IN HISTOLOGICAL SUBTYPES OF PRIMARY EXTRANODAL NON-HODGKIN LYMPHOMA
}

\author{
FARHANA MOHAMMAD MOHAIDIN ${ }^{1,2,3}$, PAVITRATHA PUSPANATHAN ${ }^{2}$, \\ NUR ASYILLA CHE JALIL ${ }^{1,3}$ and FAEZAHTUL ARBAEYAH HUSSAIN ${ }^{1,3 *}$ \\ ${ }^{1}$ Department of Pathology, School of Medical Sciences, Universiti Sains Malaysia, \\ Health Campus, 16150 Kota Bharu, Kelantan, Malaysia \\ ${ }^{2}$ Department of Pathology, Hospital Sultanah Bahiyah, Km 6, Jalan Langgar, \\ Bandar Alor Setar, 05460 Alor Setar, Kedah, Malaysia \\ ${ }^{3}$ Hospital Universiti Sains Malaysia, 16150, Kubang Kerian, Kelantan, Malaysia \\ *E-mail:faezahtul@usm.my
}

Accepted 15 September 2021, Published online 30 November 2021

\begin{abstract}
Programmed death 1 (PD-1) protein and its ligands, PD-L1 are two proteins that have been widely studied in many solid tumours. However, only limited observations were made in lymphomas, which were mainly Hodgkin lymphomas. We aimed to evaluate the expressions of PD-1 in the tumour microenvironment and PD-L1 in the tumour cells of primary extranodal non-Hodgkin lymphoma (peNHL). A cross-sectional study using 87 archived formalin-fixed paraffin-embedded tissue blocks from patients diagnosed with peNHL. Immunohistochemistry stainings for PD-1 and PD-L1 were done. The protein expressions were evaluated microscopically. The association between expressions of the PD-1 and PD-L1 with the histological subtypes of peNHL were statistically analysed. $46(52.9 \%)$ of the cases had a negative expression of PD-L1 in the tumour cells and $57(65.5 \%)$ had positive PD-1 expression in the tumour microenvironment. Significant associations were found between PD-1 and PD-L1 expressions with subtypes of peNHL $(p<0.05)$. Positive expressions of both proteins were found in diffuse large B cell lymphoma (DLBCL). Our study explored the expressions of PD-1 and PD-L1 in peNHL that has demonstrated a significant association of PD-1 and PD-L1 expressions with subtypes of peNHL, which may provide additional information to the future study of these proteins.
\end{abstract}

Key words: Primary extranodal non-Hodgkin lymphoma, PD-1, PD-L1

\section{INTRODUCTION}

Lymphomas are categorized as solid tumours of the immune system. $90 \%$ of lymphoma are NonHodgkin lymphomas (NHL) with only about $10 \%$ being Hodgkin lymphoma (HL) (Zucca, 2008). NHL can be further divided into a heterogenous group of disorders arising from B-lymphocytes, Tlymphocytes or Natural Killer (NK) cells. NHL arising from tissues outside the lymphatic systems and even from the sites without the presence of lymphoid tissues are referred to as primary extranodal lymphomas (peNHL). Diagnosing peNHL can be challenging as they have cytomorphological

* To whom correspondence should be addressed. diversities with variable histopathological classification, and many other challenges contribute to this. Krol et al. (2003) used a more liberal definition of peNHL which is an NHL that originated dominantly from an extranodal site despite the presence of disseminated disease.

The incidence of peNHL has increased substantially in the last 40 years (Zucca, 2008). This may be due to improved diagnostic procedures (particularly in the brain and gastrointestinal lymphomas). The frequency of peNHL varies in different parts of the world. In countries with high total lymphoma incidence exhibit a proportionate incidence of extranodal lymphomas (Thomas et al., 2011). A comparative study done in 2008 found there was a higher prevalence of peNHL cases in Arabs 
than in Asians (AlShemmari et al., 2008). In Malaysia, a study that was conducted at the University of Malaya from 1980 to 2012, reported 42 cases of peNHL involving the oral maxillary fascia sites (Ramanathan et al., 2014). However, no cumulative study on incidence on peNHL has been published in Malaysia.

peNHLs have been reported to originate from any anatomic site of the body (Thomas et al., 2011; Padhi et al., 2012; Mertsoylu et al., 2014; Shen et al., 2018). A Dutch study showed that the gastrointestinal tract (GIT) was the most common site of peNHL (45.7\%) (Krol et al., 2003). In contrast, the central nervous system (CNS) constituted the most common extranodal site in an Indian study (29.7\%) (Padhi et al., 2012). The types of lymphomas encountered vary widely from one extranodal site to the other. However, B cells accounted for the majority of peNHL cases among all races and sex groups (Zucca, 2008; Mishra et al., 2015; Panjwani et al., 2018; Vijayasree et al., 2019). Amongst the B cells peNHL, diffuse large B-cell lymphoma (DLBCL), marginal zone lymphoma (MZL) and follicular lymphoma (FL) accounted for over $75 \%$ of all cases (Wu et al., 2009; Farooq et al., 2014; Shen et al., 2018). The incidence of $\mathrm{T}$ cells peNHL is rare compared to B cells, which contributed about $3 \%$ of all types of peNHL and the majority are confined to the skin, such as mycosis fungoides (MF) (Padhi et al., 2012).

The microenvironment of lymphoma is composed of many cells including histiocytes, eosinophils, lymphocytes, and plasma cells. These cells interact with numerous other cells like including $\mathrm{CD}^{+}$and $\mathrm{CD}^{+} \mathrm{T}$ lymphocytes, B lymphocytes, plasma cells, or dendritic cells, via the secretion of variable chemokines and cytokines (Witkowska $\&$ Smolewski, 2018). These unique and complex microenvironment interactions are responsible for the initiation and progression of lymphomas. By influencing the microenvironment, the immune system can be exploited to promote tumour metastasis, angiogenesis, and growth (Anagnostou \& Ansell, 2017). One of the mechanisms involves programmed death-1 (PD-1) protein and its ligand (PD-L1).

In a normal situation, activated $\mathrm{T}$ cells are not triggered to attack healthy cells because healthy human cells carry a PD-L1 protein. The checkpoint protein, $\mathrm{PD}-1$ on the activated $\mathrm{T}$ cell binds to the PD-L1 of a normal cell, the immune system acknowledges the normal cell as non-pathogenic. This recognition is important as an inhibitor of the $\mathrm{T}$ cell-mediated immune response and maintaining self-tolerance in chronic infectious or inflammatory conditions. (Keir et al., 2008). Tumour cells adopt this mechanism to evade the immune response of the host for the tumour cells to survive. It has been proven that tumour cells can express PD-L1 proteins, which bind to $\mathrm{PD}-1$ on the $\mathrm{T}$ cells in the tumour microenvironment (Anagnostou \& Ansell, 2017; Zhu et al., 2019; Yu et al., 2020). This leads to decreasing $\mathrm{T}$ cell proliferation and interleukin 2 (IL-2) production, hence promotes $\mathrm{T}$ cell apoptosis, causing $\mathrm{T}$ cell exhaustion (Zou et al., 2016; Anagnostou \& Ansell, 2017; Zhu et al., 2019; Yu et al., 2020). As a result, the defence mechanism by the $\mathrm{T}$ cells is reduced.

In lymphoma, most data on PD-1 and PD-L1 expressions and their clinical relevance have been described mainly in HL and nodal DLBCL (Ok \& Young, 2017). A large study done by Kiyasu et al. (2015), in Japan involving 1253 patients, found that $37 \%(461 / 1253)$ cases were PD-L1 positive on the tumour cells of DLBCL, and had inferior overall survival compared to the patients with PD-L1 negative DLBCL. Another small study that involved 30 cases of primary testicular DLBCL found that, PD-L1 expression on the tumour cells was detected in 20 cases $(66.7 \%)$ (Zhu et al., 2019). In contrast to DLBCL, most FL tumour cells do not express PD-L1, however, PD-1 positive cells are abundant in the microenvironment of FL (Gravelle et al., 2017). Positive PD-1 expression in tumour infiltrating lymphocytes (within the microenvironment) is associated with a more favourable prognostic factor, while a low number was associated with an increased risk of histologic transformation into an aggressive lymphoma (Xu-Monette et al., 2018).

For T cells lymphoma, PD-1 is a well-known established sensitive marker of angioimmunoblastic lymphoma (AITL) (Swerdlow et al., 2017). However, the expression of PD-1 in the tumour microenvironment and PD-L1 expression on the tumour cells has not been well explored in T cell peNHL. A study by Jo et al. (2017), involving 79 cases of extranodal NK/T cells lymphoma (ENKTL) demonstrated variable expressions of PD-L1 by the tumour cells together with the infiltrating immune cells, however, the expression rates of PD-1 in the tumour cells and infiltrating immune cells were very low. The study also found that PD-L1 positive patients with lower international prognostic index (IPI) scores had a better overall survival (Jo et al., 2017).

Nivolumab and pembrolizumab are anti-PD-1 and anti-PD-L1 drugs respectively, have been successfully used in patients with different types of solid tumours including melanoma (Panjwani et al., 2018). Furthermore, PD-1 blockade had been proven to improve outcomes of patients with relapsed/ refractory HL and chronic lymphocytic leukaemia (CLL) (Ansell et al., 2015). Considering the potential availability of PD-1 and PD-L1 inhibitors, clarification of the PD-1 and PD-L1 expressions on tumour 
behaviour is crucial. Furthermore, most of the researches were conducted in western countries, which may differ from our local settings. There is also no data on PD-1 and PD-L1 expressions in peNHL in Malaysia. Herein, we conducted a study to describe PD-1 and PD-L1 expressions with histological correlation in peNHL.

\section{MATERIALS AND METHODS}

This is a single-centre retrospective cross-sectional study that included 87 cases of peNHL diagnosed in Hospital Sultanah Bahiyah (HSB), Alor Setar between January 2015 and December 2019. The study protocol was approved by Human Research Ethics Committee (HREC), Universiti Sains Malaysia (USM/ JEPeM/19010076) and Medical Research and Ethics Committee (MREC) Ministry of Health, Malaysia (NMRR-19-2217-45586).

\section{Case selection}

All cases diagnosed as peNHL within the study period were included in this study. This information was obtained from the laboratory database of the Department of Pathology, HSB. The cases then were further scrutinised to exclude those with missing and inadequate tumour tissue from the formalin-fixed paraffin-embedded (FFPE) tissue blocks and overlapping cases from the same patient. The demographic data were retrieved from the eHIS system at HSB.

\section{Immunohistochemistry staining}

Selected FFPE tissue blocks were sectioned at $3 \mu \mathrm{m}$ thickness and sent for staining for the PD- 1 and PD-L1 immunohistochemistry (IHC) stainings in the pathology laboratory of Hospital Universiti Sains Malaysia (USM). Sections were deparaffinised, followed by epitope retrieval using EnVision Flex target retrieval solution, at high $\mathrm{pH}$. All of the slides were subsequently placed in Squenza immunostainer, incubated overnight at $4{ }^{\circ} \mathrm{C}$ with Anti-PD-L1 antibody [ABCAM 28-8] and recombinant Anti-PD-1 antibody [ABCAM EPR4877(2)] respectively. The primary antibodies were prediluted to 1:500 each. Localization of the antigen-antibody was achieved using labelled polymer, EnV FLEX/HRP. The complex was visualised with substrate chromogen (Envision FLEX substrate working solution). Reactive tonsils and lymph nodes served as external positive controls and placental tissue as a negative control for both PD-1 and PD-L1 primary antibodies.

\section{Immunohistochemistry staining assessment}

A complete circumferential or partial linear cellular membrane staining of any intensity of PD-L1 expression is considered positive staining.
Cytoplasmic staining, if present, was not considered positive for scoring purposes. Non-malignant cells and immune cells within the tumour microenvironment (e.g., the reactive lymphocytes or macrophages) may also stain with PD-L1; however, these were not included in the determination of PD-L1 positivity. For PD-L1, based on a previous study (Qian et al., 2020), the samples with $<5 \%$ stained tumours cells were defined as negative. For $\geq 5 \%$ positive PD-L1 stained on the tumour cells were defined as positive regardless of the intensity. Thus, based on the previous study, we selected 10 representative high power fields (HPF) $(400 \times)$ using a microscope (Olympus model CX31) and counted 100 tumour cells for each HPF and used cut off value of $5 \%$ as positive staining in this study.

PD-1 was detected in the tumour microenvironment with membranous staining. The assessment and scoring were done according to the findings from the previous study (Ko et al., 2011). PD-1 expressions were assessed at three different HPF $(400 \times)$ using a microscope (Olympus model CX31), the number of PD-1 positive cells in the tumour microenvironment were counted and the average value was recorded. The samples were classified as positive for $>20$ cells/HPF and negative for $\leq 20$ cells/HPF.

\section{Statistical analysis}

Statistical analysis was performed with the SPSS version 26.0. Descriptive analysis was used for frequency distributions of categorical variables and median distributions of a continuous variable. The association of clinicopathological characteristic with PD-1 and PD-L1 expressions were analysed using the Pearson Chi-Square test or Fisher's Exact test. The level of significance in this study was set as $p$-value $<0.05$.

\section{RESULTS}

\section{Demographic characteristics}

A total of 410 cases were diagnosed as lymphoma in Hospital Sultanah Bahiyah within the 5 years of the study period, with $334(81.5 \%)$ being NHLs, and $76(18.5 \%)$ cases of HL. 112 (33.4\%) cases of NHL were peNHL in nature. 87 cases that fulfilled the inclusion and exclusion criteria, were then included in this study. The demographic characteristics are presented in Table 1 . The median age of 61 years old (range 8 to 88 years). Of these patients $51(58.6 \%)$ were male and $36(41.4 \%)$ were female. Malay ethnicity was the highest, 69 (79.3\%), followed by Chinese, 13 (14.9\%), Siamese, 3 (3.4\%) and Indian, $2(2.3 \%)$. GIT was the most common site, $30(34.5 \%)$ involved in this study. The list of the subtypes of the peNHL in this study is shown in 
Table 1. Demographic characteristics of peNHL $(n=87)$

\begin{tabular}{|c|c|c|}
\hline Variables & Median & $n(\%)$ \\
\hline \multicolumn{3}{|l|}{ Age group } \\
\hline$<60$ years old & 61 & $43(49.4)$ \\
\hline$>60$ years old & & $44(50.6)$ \\
\hline \multicolumn{3}{|l|}{ Sex } \\
\hline Male & & $51(58.6)$ \\
\hline Female & & $36(41.4)$ \\
\hline \multicolumn{3}{|l|}{ Ethnic } \\
\hline Malay & & $69(79.3)$ \\
\hline Chinese & & $13(14.9)$ \\
\hline Indian & & $2(2.3)$ \\
\hline Siamese & & $3(3.4)$ \\
\hline \multicolumn{3}{|l|}{ General subtype } \\
\hline B cell lymphoma & & $79(90.8)$ \\
\hline $\mathrm{T}$ cell lymphoma & & $8(9.2)$ \\
\hline \multicolumn{3}{|l|}{ Locations } \\
\hline GIT & & $31(35.6)$ \\
\hline Head and neck & & $29(33.3)$ \\
\hline CNS & & $5(5.7)$ \\
\hline Genitourinary & & $8(9.2)$ \\
\hline Skin and musculoskeletal & & $4(4.6)$ \\
\hline Mediastinum & & $3(3.5)$ \\
\hline Breast & & 1(1.1) \\
\hline Retroperitoneum & & $2(2.3)$ \\
\hline CVS & & 1(1.1) \\
\hline Lung & & $3(3.5)$ \\
\hline
\end{tabular}

GIT: Gastrointestinal Tract, CNS: Central Nervous System, CVS Cardiovascular System.

Table 4. Amongst the B cell lymphomas (79, 90.8\%), DLBCL was the most common histological subtype observed $(52,65.8 \%)$ with germinal centre (GCB) variant $(28,35.4 \%)$ and non GCB variant $(24,30.4 \%)$. There were 3 FL (3, 3.8\%), MZL-MALT (19, 24.1\%), Burkitt lymphoma $(2,2.5 \%)$ and one each of SLL, plasmablastic and large B not subtyped $(1.3 \%$ respectively). As for $\mathrm{T}$ cell lymphomas (8, 9.2\%), there were 3 cases each of anaplastic large cell lymphoma (ALCL) and not subtyped T cell (37.5\% respectively) with 2 cases of MF (25\%).

\section{PD-1 and PD-L1 immunohistochemistry}

Protein expression for PD-L1 in the tumour cells and PD-1 in the tumour microenvironment were evaluated in all 87 samples. The expressions are summarized in Table 2. The representative image of PD-L1 and PD-1 are shown in Figures 1 and 2. 41 cases $(47.1 \%)$ showed immunopositivity for PD-L1 in the tumour cells, while $46(52.9 \%)$ cases had negative expression. 57 cases $(65.5 \%)$ were positive and 30 $(34.5 \%)$ were negative for expression of PD-1 in the tumour microenvironment. The expression of PD-1 in the tumour microenvironment was not significantly associated with the expression of PD-L1 in the tumour cells $(p>0.05)$.

Table 3 summarises the association between PD-1 in the tumour microenvironment and PD-L1 in the tumour cells with demographic factors. In this study, no significant associations were found between the PD-1 and PD-L1 expressions, with the demographic factors. PD-L1 expression was positive in the peNHL of male patients $(20,39.2 \%)$ and, in lymphomas of CNS $(3,60.0 \%)$, skin and musculoskeletal $(4,100 \%$ respectively) as well as mediastinum $(2,66.7 \%)$. Positive PD-L1 expression was also observed in the T cell lymphomas $(6,75.0 \%)$ when compared to the B cell lymphomas $(35,44.3 \%)$. For PD-1 in the tumour microenvironment, more cases with positive expression were observed in the group of age less than $60(26,60.5 \%)$ compared to that age equal to or more than 60 years old.

In the B cell subtypes, both PD-1 and PD-L1 expressions were positive in DLBCL compared to the other subtypes of B NHLs. Within the DLBCL variants, the number of cases with positive expression of PD-L1 was noted to be higher in the non GCB $(17,70.8 \%)$ compared to the GCB subtypes $(14,50.0 \%)$. Whilst tumour microenvironment PD-1 positive expression was equal in both variants of DLBCL. The other aggressive B NHLs such as plasmablastic lymphoma, Burkitt lymphoma and unclassified large B cells had negative expressions for both PD-1 and PD-L1 immunostainings.

Table 2. The PD-1 and PD-L1 expressions in peNHL and their associations

\begin{tabular}{llcccc}
\hline & & \multicolumn{2}{c}{ PD-L1 expression in the tumour cells } & & \\
\cline { 3 - 4 } & $\begin{array}{c}\text { Positive } \\
n(\%)\end{array}$ & $\begin{array}{c}\text { Negative } \\
n(\%)\end{array}$ & & TOTAL & $p$-value \\
\hline $\begin{array}{l}\text { PD-1 expression in the } \\
\text { tumour microenvironment }\end{array}$ & Positive & $\begin{array}{c}29(50.9) \\
12(40)\end{array}$ & $\begin{array}{c}28(49.1) \\
18(60)\end{array}$ & $\begin{array}{c}57(65.5) \\
30(34.5)\end{array}$ & $0.33^{\mathrm{a}}\left(\chi^{2}(\mathrm{df})=1\right)$ \\
\hline TOTAL & & $41(47.1)$ & $46(52.9)$ & & $87(100)$ \\
\hline
\end{tabular}

a Fisher's exact test.

p-value $<0.05$ were considered significant. 


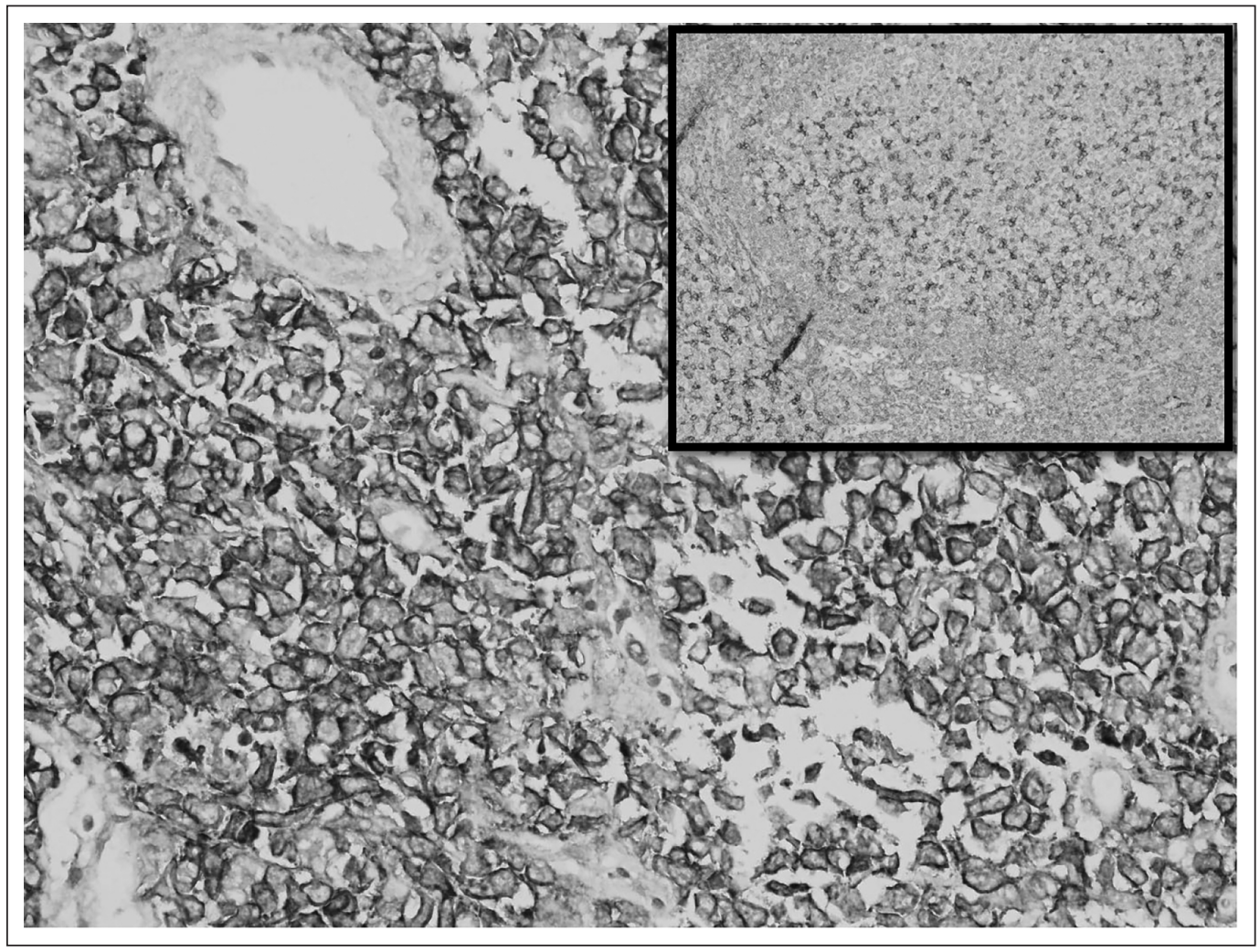

Fig. 1. DLBCL-GCB subtypes of peNHL stained positive for PD-L1. The PD-L1 staining is mainly membranous (photographed at $\times 400$ magnification). The inset picture shows positive control with membranous staining of the germinal centre using tissue from the reactive lymph node.

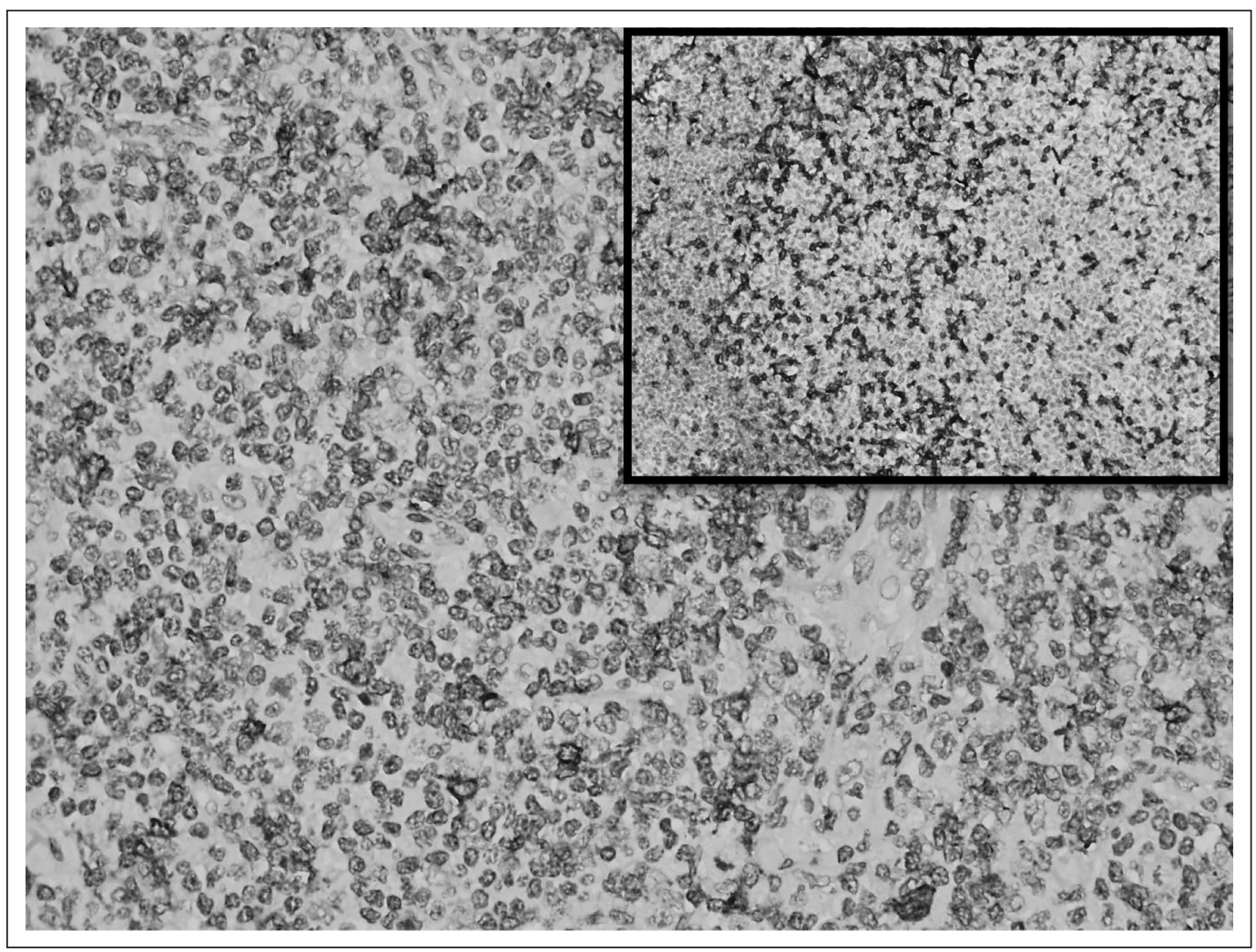

Fig. 2. DLBCL-GCB subtypes of peNHL stained positive for PD-1 in the tumour microenvironment. The PD-1 staining is mainly membranous (photographed at $\times 400$ magnification). The inset picture shows positive control with membranous staining of the germinal centre using tissue from the reactive lymph node. 
Table 3. The association between PD-1 and PD-L1 expressions with demographic factors, general subtypes and locations of peNHL

\begin{tabular}{|c|c|c|c|c|c|c|c|}
\hline \multirow{2}{*}{ Variables } & \multirow{2}{*}{$n$} & \multicolumn{3}{|c|}{$\begin{array}{l}\text { PD-1 expression in the } \\
\text { tumour microenvironment }\end{array}$} & \multicolumn{3}{|c|}{$\begin{array}{l}\text { PD-L1 expression of the } \\
\text { tumour cells }\end{array}$} \\
\hline & & $\begin{array}{c}\text { Positive } \\
n(\%)\end{array}$ & $\begin{array}{c}\text { Negative } \\
n(\%)\end{array}$ & $\begin{array}{c}p \\
\text { value }\end{array}$ & $\begin{array}{c}\text { Positive } \\
(\%)\end{array}$ & $\begin{array}{c}\text { Negative } \\
n(\%)\end{array}$ & $\begin{array}{c}p \\
\text { value }\end{array}$ \\
\hline \multicolumn{8}{|l|}{ Age } \\
\hline$<60$ & 43 & $26(60.5)$ & $17(39.5)$ & \multirow[t]{2}{*}{$0.32^{\mathrm{a}}$} & 19(44.2) & $24(55.8)$ & \multirow[t]{2}{*}{$0.58^{a}$} \\
\hline$>60$ & 44 & $13(29.5)$ & $31(70.5)$ & & $22(50.0)$ & $22(50.0)$ & \\
\hline \multicolumn{8}{|l|}{ Sex } \\
\hline Male & 51 & $37(72.5)$ & $14(27.5)$ & \multirow{2}{*}{$0.10^{\mathrm{a}}$} & $20(39.2)$ & $31(60.8)$ & \multirow{2}{*}{$0.07^{a}$} \\
\hline Female & 36 & $20(55.6)$ & $16(44.4)$ & & $21(58.3)$ & $15(41.7)$ & \\
\hline \multicolumn{8}{|l|}{ Ethnicity } \\
\hline Malay & 69 & $49(71.0)$ & $20(29.0)$ & \multirow[t]{4}{*}{$0.13^{b}$} & $32(46.4)$ & $37(53.6)$ & \multirow[t]{4}{*}{$0.95^{b}$} \\
\hline Chinese & 13 & $6(46.2)$ & $7(53.8)$ & & $7(53.8)$ & $6(46.2)$ & \\
\hline Indian & 2 & $1(50.0)$ & $1(50.0)$ & & $1(50.0)$ & $1(50.0)$ & \\
\hline Others & 3 & $1(33.3)$ & $2(66.7)$ & & $1(33.3)$ & $2(66.7)$ & \\
\hline \multicolumn{8}{|l|}{ General subtype } \\
\hline B cell lymphoma & 79 & $52(65.8)$ & $27(34.2)$ & \multirow[t]{2}{*}{$0.85^{\mathrm{a}}$} & $35(44.3)$ & $44(55.7)$ & \multirow[t]{2}{*}{$0.09^{a}$} \\
\hline T cell lymphoma & 8 & $5(62.5)$ & $3(37.5)$ & & $6(75.0)$ & $2(25.0)$ & \\
\hline \multicolumn{8}{|l|}{ Locations } \\
\hline GIT & 31 & $19(61.3)$ & 12(38.7) & \multirow[t]{10}{*}{$0.07^{b}$} & $14(45.2)$ & $17(54.8)$ & \multirow{10}{*}{$0.46^{\mathrm{b}}$} \\
\hline Head \& neck & 29 & $22(75.9)$ & $7(24.1)$ & & $11(37.9)$ & $18(62.1)$ & \\
\hline CNS & 5 & $5(100)$ & $0(0)$ & & $3(60.0)$ & $2(40.0)$ & \\
\hline Genitourinary & 8 & $5(62.5)$ & $3(37.5)$ & & $4(50.0)$ & $4(50.0)$ & \\
\hline Skin \& musculoskeletal & 4 & $1(50.0)$ & $1(50.0)$ & & $4(100.0)$ & $0(0)$ & \\
\hline Mediastinum & 3 & $0(0)$ & $3(100)$ & & $2(66.7)$ & $1(33.3)$ & \\
\hline Breast & 1 & $1(100)$ & $0(0)$ & & $1(100.0)$ & $0(0)$ & \\
\hline Retroperitoneum & 2 & $1(50.0)$ & $1(50.0)$ & & $1(50.0)$ & $1(50.0)$ & \\
\hline CVS & 1 & $0(0)$ & $1(100)$ & & $0(0)$ & $1(100)$ & \\
\hline Lung & 3 & $1(33.3)$ & $2(66.7)$ & & $1(33.3)$ & $2(66.7)$ & \\
\hline
\end{tabular}

a Fisher's exact test.

bPearson Chi-Square test.

p-value $<0.05$ were considered significant.

Table 4. The association between expression of PD-1 and PD-L1 with subtypes peNHL

\begin{tabular}{|c|c|c|c|c|c|c|c|}
\hline \multirow{2}{*}{ Lymphoma Subtypes } & \multirow{2}{*}{$n$} & \multicolumn{3}{|c|}{$\begin{array}{l}\text { PD-1 expression in the } \\
\text { tumour microenvironment }\end{array}$} & \multicolumn{3}{|c|}{$\begin{array}{l}\text { PD-L1 expression of the } \\
\text { tumour cells }\end{array}$} \\
\hline & & $\begin{array}{l}\text { Positive } \\
n(\%)\end{array}$ & $\begin{array}{l}\text { Negative } \\
n(\%)\end{array}$ & $\begin{array}{c}p \\
\text { value }\end{array}$ & $\begin{array}{l}\text { Positive } \\
\text { (\%) }\end{array}$ & $\begin{array}{l}\text { Negative } \\
n(\%)\end{array}$ & $\begin{array}{c}p \\
\text { value }\end{array}$ \\
\hline \multicolumn{8}{|l|}{ B cells } \\
\hline Follicular & 3 & $0(0)$ & $3(100)$ & & 1(33.3) & $2(66.7)$ & \\
\hline DLBCL-GCB & 28 & $16(57.1)$ & $12(42.9)$ & & $14(50.0)$ & $14(50.0)$ & \\
\hline DLBCL-NGCB & 24 & $13(54.2)$ & $11(45.8)$ & & $17(70.8)$ & $7(29.2)$ & \\
\hline MZL-MALT & 19 & 19(100) & $0(0)$ & & $2(10.5)$ & $17(89.5)$ & \\
\hline Burkitt & 2 & $0(0)$ & $2(100)$ & & $0(0)$ & $2(100)$ & \\
\hline SLL & 1 & $1(100)$ & $0(0)$ & $0.014^{b}$ & $0(0)$ & $1(100)$ & $0.008^{b}$ \\
\hline Plasmablastic & 1 & $0(0)$ & $1(100)$ & & $0(0)$ & $1(100)$ & \\
\hline Large B cells & 1 & $0(0)$ & $1(100)$ & & $1(100)$ & $0(0)$ & \\
\hline \multicolumn{8}{|l|}{ T cells } \\
\hline ALCL & 3 & $2(66.7)$ & $1(33.3)$ & & $2(66.7)$ & 1(33.3) & \\
\hline Mycosis Fungoides & 2 & $1(50.0)$ & $1(50.0)$ & & $2(100.0)$ & $0(0)$ & \\
\hline $\mathrm{T}$ cells & 3 & $2(66.7)$ & $1(33.3)$ & & $2(66.7)$ & 1(33.3) & \\
\hline
\end{tabular}

b Pearson Chi-Square test.

$p$-value $<0.05$ were considered significant. 
Interestingly, the low-grade ones like MZL mucosaassociated lymphoid tumour (MALT) and SLL had a positive expression of PD-1 in the tumour microenvironment $(19,100 \% \& 1,100 \%$ respectively), but only two cases $(10.5 \%)$ of MZL-MALT were positive for PD-L1 expression in the tumour cells and PD-L1 was negative in all of SLL. The three cases of FL, which is another low-grade B NHL, was negative for PD-1 (100\%) with 1 positive for PD-L1 expression and two were negative. As for the T cell peNHLs, all the subtypes had variable positive expressions of both PD-1 and PD-L1. ALCL (3) and the unclassified T cells NHLs (3) had two cases each that express PD-1 in the tumour microenvironment as well as PD-L1 in the tumour cells. The two mycosis fungoides cases on the other hand had only half of the case (50\%) was positive for PD-1 expression with $100 \%$ PD-L1 positive expression. There was a significant association between the subtypes of peNHL with an expression of PD-1 in the tumour microenvironment and PD-L1 expressions on the tumour cells $(p<0.05)$. The summary of these results is shown in Table 4.

\section{DISCUSSION}

Primary extra-nodal non-Hodgkin lymphoma (peNHL) is a heterogeneous disease about histopathology, anatomic, aetiological, geographical and ethnic diversities (Krol et al., 2003). There is no clear definition of Ann Arbor classification for primary nodal lymphoma and peNHL. We adapted from the previous study by Krol et al. (2003) which used the definition of peNHL as no or minor nodal involvement, together with a dominant extranodal component that is present clinically.

This study involved 87 cases of peNHL that have been diagnosed in a 5-year-period at Hospital Sultanah Bahiyah, Alor Setar. The majority of the patients were elderly, with a median age of 61 years old. This finding is comparable to the studies that were done in Thailand which showed the median age of 63 years old (Nanthakwang et al., 2019) and, in Japan with a median age of 61 years old (Fujita et al., 2009) in their selected patients for the studies. However, a study from India (Padhi et al., 2012) reported the mean age of peNHL patients to be 43 years old, which was younger than our current study. The increased incidence of peNHL in elderly patients is likely due to compromised immune function and age-related accumulation of environmental exposure (Fujita et al., 2009).

A male preponderance was noted in this study which is consistent with several previous studies (Fujita et al., 2009; Pai et al., 2017; Nanthakwang et al., 2019). In our study, the GIT system is the commonest organ involved by peNHL (34.5\%). The pattern of involvement in our study was similar to that were reported in the Western population $(\mathrm{Wu}$ et al., 2009), Thailand (Nanthakwang et al., 2019) and India (Pai et al., 2017), with the stomach being the most common site.

The majority of the cases in this study were B cell lymphomas $(90.8 \%)$ and only $9.2 \%$ were $\mathrm{T}$ cell lymphomas. This correlates well with other studies in which the majority of the peNHL were of B cells lymphoma (Zucca, 2008; Thomas et al., 2011; Vannata \& Zucca, 2015; Vijayasree et al., 2019) with DLBCL being the most common histological subtype $(59.8 \%)$. These were similar to the findings in studies from Thailand (Nanthakwang et al., 2019), United States (Wu et al., 2009), Japan (Fujita et al., 2009) and India (Pai et al., 2017).

Programmed death receptor 1 (PD-1) is an inhibitory receptor that is expressed on the surface of activated $\mathrm{T}$ cells. It is normally involved in immune tolerance and the prevention of tissue damage associated with chronic inflammation (Akinleye \& Rasool, 2019). The interactions of PD-1 with its ligands, PD-L1 and PD-L2 cause inhibition of T-cell receptors signals by down-regulating $\mathrm{T}$-cell activation and proliferation. Hence, blunting the T-cell-mediated anti-tumour immune responses.

Many tumour cells can self-up-regulate the expression of PD-L1 in them, which then acts as a mechanism to evade the natural immune responses. Many studies have revealed PD-L1 expression on tumour cells, and they were associated with an unfavourable prognosis (Wang et al., 2016). Many of the previous studies on the protein expressions of PD-1 and PD-L1 were done on nodal lymphoma and HL. Therefore, there is a need to understand these proteins behaviour in extranodal lymphomas.

In our study, the majority of peNHL tumour cells were negative for PD-L1 (52.9\%). There was a significant association found between the expression of PD-L1 in tumour cells and the subtypes of peNHL $(p<0.05)$. A similar finding was observed in a study from China involving 92 patients diagnosed with nodal NHL, where a significant association between expression of PD-L1 and subtypes of lymphoma was identified (Yang \& Hu, 2019). The most common subtype of the peNHL in our study was DLBCL (52, $59.8 \%$ ) with 31 (59.6\%) showed positive expression of PD-L1. This finding is consistent with a small study involving 30 cases of primary testicular DLBCL, in which PD-L1 expression on tumour cells was detected in 20 cases (66.7\%) (Zhu et al., 2019). In a study done by Kiyasu et al. (2015), in Japan involving 1253 patients diagnosed with nodal DLBCL, the researchers found that $37 \%(461 / 1253)$ of cases were PD-L1 positive and had inferior overall survival compared with PD-L1 negative DLBCL 
patients. One recent study done by Yang and $\mathrm{Hu}$ (2019) reported that PD-L1 positive expression in the tumour cells predicted poor survival in patients with DLBCL in China. All of the studies (Kiyasu et al., 2015; Gravelle et al., 2017; Yang \& Hu, 2019) that have investigated PD-L1 levels in DLBCL had reported that a higher number of positive expressions were observed in the non GCB DLBCL, which are consistent with our findings that showed cases with positive PD-L1 expression was higher in the non GCB DLBCL $(17,70.8 \%)$. About $20 \%$ of DLBCL were reported to have structural anomalies on chromosome 9p24.1 which was significantly correlated with PD-L1 expression in nodal DLBCL (Gravelle et al., 2017). However, whether this is also similar in peNHL DLBCL is still questionable, and warrant further investigations.

On the other hand, we found that most of our cases of peNHL showed PD-1 immunopositivity in the tumour microenvironment $(55.8 \%)$ with almost equal expressions in both GCB and non GCB DLBCL. A high number of $\mathrm{PD}-1$ in tumour infiltrating lymphocytes in DLBCL is associated with favourable clinical features and prognosis (Song et al., 2019). However, this notion was not explored in our current study due to limited resources.

In contrast to DLBCL, most FL tumour cells did not express PD-L1 (Panjwani et al., 2018). Only 3 cases of extranodal FL were included in our study, with only 1 showing PD-L1 expression in the tumour cells and all 3 displayed PD-1 negative expressions in the tumour microenvironment. This is conflicting with the prior study (Xu-Monette et al., 2018) which was done in nodal FL, that had demonstrated PD-1 positive cells were abundant in the tumour microenvironments. Another study has reported a correlation between low PD-1 positive cell counts with increased risk of transformation into a higher histological grade of FL or DLBCL (Panjwani et al., 2018). While the other subtypes of B cells peNHL in this study were found to be negative for PD-L1 expression in the tumour cells as well as PD-1 expression in the tumour microenvironment. Similar findings were reported by a study involving 403 patients of nodal B cell lymphoma in Switzerland, the number of cases with PD-1 positive expression in the tumour microenvironment was exceptionally low in mantle cell lymphoma (MCL) and SLL (Muenst et al., 2010). These results were similar to that from a study by Panjwani et al. (2018), where they also found a low number of cases with positive PD-L1 expression in MCL, SLL, MZL-MALT and lymphoblastic lymphoma.

We faced difficulties in interpreting the expressions of PD-1 and PD-L1 in the T cells peNHL, as their expressions were also observed in the reactive $\mathrm{T}$ lymphocytes in the tumour microenvironment. In addition, it is well established that PD-1 is a specific and diagnostic marker of angioimmunoblastic lymphoma (AITL) (Swerdlow et al., 2017) which is used to identify the neoplastic $\mathrm{T}$ follicular helper cells. However, of the 8 cases of $\mathrm{T}$ cells peNHL in our study, none was AITL. All of the $\mathrm{T}$ cell peNHL in our study showed positive PD-L1 (100\%) expression in the tumour cells as well as variable PD-1 expression $(62.5 \%)$ in the tumour microenvironment. The expression of PD-L1 in the $\mathrm{T}$ cell of our study was comparable to the finding in a study done by Jo et al. (2017), on ENKTL, nasal type, which showed positive expression of PD-L1 (97.9\%). However, the PD-1 expression was different from that of our study, in which the positive expression of PD-1 in tumour cells and infiltrating immune cells were very low (1.3\%) in their study (Jo et al., 2017). However, there were no definite ENKTL subtypes included in our study. Two out of 3 cases $(66.7 \%)$ of ALCL in our study had a positive expression for PD-L1 in the tumour cells, which were consistent with a study by Panjwani et al. (2018), that showed 12 of $15(80 \%)$ ALCL demonstrated positive expression of PD-L1. As many of the T cell lymphomas are associated with EBV infection, it was discovered that EBV infection promotes PD-L1 expression in tumour cells (Green et al., 2012). However, this was not explored in our study.

\section{CONCLUSION}

In our study, we found that most of the subtypes of peNHL were of the B NHLs, which the most common one was DLBCL. The common site affected by extranodal lymphoma was the GIT. Despite the small number of cases recruited in this study, there was evidence of a statistically significant association of the PD-1 and PD-L1 protein expressions with the subtypes of peNHLs.

There are several limitations to this present study. First, this was a single-centre retrospective study with a small sample size of 87 patients where patients' outcome was not included; therefore, a prospective study with a larger number of cases and correlation with the patients' disease outcome is warranted to understand the expressions of PD-1 and PD-L1 in peNHL in association with the clinical behaviour. To overcome these problems, we hope to increase the sample size by collaborating with other institutions from other states. Secondly, immunohistochemistry is a multi steps technique and is influenced by multiple factors. One of the crucial factors is that different antibody clones that are used in different studies and have different sensitivity levels as well as the different cut-off values of the positive cellular staining. Standardization of clone 
used and positive cut-off values are important to establish more significant findings. In addition, semiquantitative assessment of the staining using manual techniques increases the inter-observer variabilities. Therefore, with the use of artificially intelligent devices that can ensure the assessment, the immunostaining is more objective and precise. Besides that, molecular testings may provide additional information in establishing the understanding of the biology of PD-1 and PD-L1 in peNHL.

In summary, our study has found a significant association between expressions on PD-1 and PD-L1 within subtypes of peNHL. These observations may provide additional information on the knowledge of these proteins expressions in peNHL, which can be utilised as a basis to explore their molecular biology and further understand their behaviour that may contribute to the development of targeted therapy in lymphoma.

\section{ACKNOWLEDGEMENTS}

We thank the administration Hospital Sultanah Bahiyah, Alor Setar, Kedah and Hospital Universiti Sains Malaysia, Kubang Kerian, Kelantan for granting the permission to conduct this research. This research was co-supported by RUI Grant 1001/ PPSP/8012247 and Bridging Grant 304/PPSP/6316134 from the School of Medical Sciences, Universiti Sains Malaysia.

\section{REFERENCES}

Akinleye, A. \& Rasool, Z. 2019. Immune checkpoint inhibitors of PD-L1 as cancer therapeutics. Journal of Hematology and Oncology, 12(1): 1-13.

AlShemmari, S.H., Ameen, R.M. \& Sajnani, K.P. 2008. Extranodal lymphoma: A comparative study. Hematology, 13(3): 163-169.

Anagnostou, T. \& Ansell, S.M. 2017. Responses and response evaluation of immune checkpoint inhibitors in lymphoma. Annals of Lymphoma, 1: 6 .

Ansell, S.M., Lesokhin, A.M., Borrello, I., Halwani, A., Scott, E.C., Gutierrez, M., Schuster, S.J., Millenson, M.M., Cattry, D., Freeman, G.J., Rodig, S.J., Chapuy, B., Ligon, A.H., Zhu, L., Grosso, J.F., Kim, S.Y., Timmerman, J.M., Shipp, M.A. \& Armand, P. 2015. PD-1 blockade with nivolumab in relapsed or refractory Hodgkin's lymphoma. New England Journal of Medicine, 372(4): 311319.
Farooq, S., Reshi,R., Hassan, Z. , Nazir, N., Beigh, A. \& Abass, F. 2014. Histopathological spectrum of primary extranodal non hodgkin's lymphomas in Kashmir valley A 5 years study. International Journal of Biological \& Medical Research, 5(4): 4654-4659.

Fujita, A., Tomita, N., Fujita, H., Motohashi, K., Hyo, R., Yamazaki, E., Hattori, M., Fujisawa, S., Kanamori, H., Ogawa, K., Motomura, S., Kodama, F. \& Ishigatsubo, Y. 2009. Features of primary extranodal lymphoma in Kanagawa, a human T-cell leukemia virus type 1 nonendemic area in Japan. Medical Oncology, 26(1): 49-54.

Gravelle, P., Burroni, B., Péricart, S., Rossi, C., Bezombes, C., Tosolini, M., Damotte, D., Brousset, P., Fournié, J.J. \& Laurent, C. 2017. Mechanisms of PD-1/PD-L1 expression and prognostic relevance in non-Hodgkin lymphoma: A summary of immunohistochemical studies. Oncotarget, 8(27): 44960-44975.

Green, M.R., Rodig, S., Juszczynski, P., Ouyang, J., Sinha, P., O’Donnell, E., Neuberg, D. \& Shipp, M.A. 2012. Constitutive AP-1 activity and EBV infection induce PD-11 in Hodgkin lymphomas and posttransplant lymphoproliferative disorders: Implications for targeted therapy. Clinical Cancer Research, 18(6): 1611-1618.

Jo, J.C., Kim, M., Choi, Y., Kim, H.J., Kim, J.E., Chae, S.W., Kim, H. \& Cha, H.J. 2017. Expression of programmed cell death 1 and programmed cell death ligand 1 in extranodal NK/T-cell lymphoma, nasal type. Annals of Hematology, 96(1): 25-31.

Keir, M.E., Butte, M.J., Freeman, G.J. \& Sharpe, A.H. 2008. PD-1 and its ligands in tolerance and immunity. Annual Review of Immunology, 26: 677-704.

Kiyasu, J., Miyoshi, H., Hirata, A., Arakawa, F., Ichikawa, A., Niino, D., Sugita, Y., Yufu, Y., Choi, I., Abe, Y., Uike, N., Nagafuji, K., Okamura, T., Akashi, K., Takayanagi, R., Shiratsuchi, M. \& Ohshima, K. 2015. Expression of programmed cell death ligand 1 is associated with poor overall survival in patients with diffuse large B-cell lymphoma. Blood, 126(19): 2193-2201.

Ko, Y.S., Oh, Y.H., Park, C.K., Kim, W.Y., Han, H.S., Lim, S.D., Hwang, T.S. \& Kim, W.S. 2011. Prognostic implication of programmed death-1positive tumor-infiltrating lymphocytes in diffuse large B-cell lymphoma. Korean Journal of Pathology, 45(6): 573-581.

Krol, A.D.G., le Cessie, S., Snijder, S., Kluin-Nelemans, J.C., Kluin, P.M. \& Noordijk, E.M. 2003. Primary extranodal non-Hodgkin's lymphoma (NHL): The impact of alternative definitions tested in the Comprehensive Cancer Centre West populationbased NHL registry. Annals of Oncology, 14(1): 131-139. 
Mertsoylu, H., Muallaoglu, S., Besen, A.A., Erdogdu, S., Sezer, A., Sedef, A.M., Kose, F., Arican, A. \& Ozyilkan, O. 2014. Primary extranodal nonHodgkin's lymphoma: Clinicopathological features, survival and treatment outcome in two cancer centers of southern Turkey. Asian Pacific Journal of Cancer Prevention, 15(17): 72077211.

Mishra, P., Das, S., Kar, R., Jacob, S. \& Basu, D. 2015. Primary extranodal non-Hodgkin lymphoma: A 3-year record-based descriptive study from a tertiary care center in Southern India. Indian Journal of Pathology and Microbiology, 58(3): 296-300.

Muenst, S., Hoeller, S., Willi, N., Dirnhofer, S. \& Tzankov, A. 2010. Diagnostic and prognostic utility of PD-1 in B cell lymphomas. Disease Markers, 29(1): 47-53.

Nanthakwang, N., Rattarittamrong, E., Rattanathammethee, T., Chai-Adisaksopha, C., Tantiworawit, A., Norrasethada, L. \& Ya-In, C. 2019. Clinicopathological study and outcomes of primary extranodal lymphoma. Hematology Reports, 11(4): 79-83.

Ok, C.Y. \& Young, K.H. 2017. Checkpoint inhibitors in hematological malignancies. Journal of Hematology and Oncology, 10(1): 103.

Padhi, S., Paul, T.R., Challa, S., Prayaga, A.K., Rajappa, S., Raghunadharao, D. \& Sarangi, R. 2012. Primary extra nodal non hodgkin lymphoma: A 5 year retrospective analysis. Asian Pacific Journal of Cancer Prevention, 13(10): 4889-4895.

Pai, A., Kannan, T., Balambika, R. \& Vasini, V. 2017. A study of clinical profile of primary extranodal lymphomas in a tertiary care institute in South India. Indian Journal of Medical and Paediatric Oncology, 38(3): 251-255.

Panjwani, P.K., Charu, V., DeLisser, M., MolinaKirsch, H., Natkunam, Y. \& Zhao, S. 2018. Programmed death-1 ligands PD-L1 and PD-L2 show distinctive and restricted patterns of expression in lymphoma subtypes. Human Pathology, 71: 91-99.

Qian, J., Meng, H., Lv, B., Wang, J., Lu, Y., Li, W. \& Zhao, S. 2020. TLR4 expression is associated with PD-L1 expression and indicates a poor prognosis in patients with peripheral T-cell lymphomas. Pathology Research and Practice, 216(3): 47434756.

Ramanathan, A., Mahmoud, H.A.R., Hui, L.P., Mei, N.Y., Valliappan, V. \& Zain, R.B. 2014. Oral extranodal non Hodgkin's lymphoma: Series of forty two cases in Malaysia. Asian Pacific Journal of Cancer Prevention, 15(4): 1633-1637.
Shen, H., Wei, Z., Zhou, D., Zhang, Y., Han, X., Wang, W., Zhang, L.U., Yang, C. \& Feng, J. 2018. Primary extra-nodal diffuse large b-cell lymphoma: A prognostic analysis of 141 patients. Oncology Letters, 16(2): 1602-1614.

Song, M.K., Park, B.B. \& Uhm, J. 2019. Understanding immune evasion and therapeutic targeting associated with PD-1/PD-L1 pathway in diffuse large B-cell lymphoma. International Journal of Molecular Sciences, 20(6): 1-16.

Swerdlow, S.H., Campo, E., Harris, N.L., Jaffe, E.S., Pileri, S.A., Stein, H. \& Thiele, J. 2017. WHO Classification of Tumours of Haematopoeietic and Lymphoid Tissues. Revised 4th Ed. Internatioal Agency for Research on Cancer (IARC), Lyon, France.

Thomas, A.G., Vaidhyanath, R., Kirke, R. \& Rajesh, A. 2011. Extranodal lymphoma from head to toe: Part 1, the head and spine. American Journal of Roentgenology, 197(2): 350-356.

Vannata, B. \& Zucca, E. 2015. Primary extranodal B-cell lymphoma: Current concepts and treatment strategies. Chinese Clinical Oncology, 4(1): 1-17.

Vijayasree, M., Sitamahalakshmi, G., PadmavathiDevi, C., Sasikala, S. \& Reddy, G.S. 2019. A study of clinical profile of primary extra nodal lymphomas at tertiary care hospital. International Journal of Scientific and Research Publications, 9(9): 247-251.

Wang, X., Teng, F., Kong, L. \& Yu, J. 2016. PD-L1 expression in human cancers and its association with clinical outcomes. OncoTargets and Therapy, 9: 5023-5039.

Witkowska, M. \& Smolewski, P. 2018. Immune checkpoint inhibitors to treat malignant lymphomas. Journal of Immunology Research, 2018: 1982423.

Wu, X.C., Andrews, P., Chen, V.W. \& Groves, F.D. 2009. Incidence of extranodal non-Hodgkin lymphomas among whites, blacks, and Asians/ Pacific Islanders in the United States: Anatomic site and histology differences. Cancer Epidemiology, 33(5): 337-346.

Xu-Monette, Z.Y., Zhou, J. \& Young, K.H. 2018. PD-1 expression and clinical PD-1 blockade in B-cell lymphomas. Blood, 131(1): 68-83.

Yang, J. \& Hu, G. 2019. Significance of PD-L1 in the diagnosis and treatment of B-cell malignant lymphoma. Oncology Letters, 17(3): 3382-3386. 
Yu, W., Hua, Y., Qiu, H., Hao, J., Zou, K., Li, Z., Hu, S., Guo, P., Chen, M., Sui, S., Xiong, Y., Li, F., Lu, J., Guo, W., Luo, G. \& Deng, W. 2020. PD-L1 promotes tumor growth and progression by activating WIP and $\beta$-catenin signaling pathways and predicts poor prognosis in lung cancer. Cell Death and Disease, 11: 506.

Zhu, D., Zhu, J., Yu, W., Hong, P., Fan, Y., Zhang, Z., Li, J., He, Q., Han, W., Shen, C. \& Jin, J. 2019. Expression of programmed cell death-ligand 1 in primary testicular diffuse large B cell lymphoma: A retrospective study. Oncology Letters, 18(3): 2670-2676.
Zou, W., Wolchok, J.D., \& Chen, L. 2016. PD-L1 (B7-H1) and PD-1 pathway blockade for cancer therapy. Science Translational Medicine, 8(328): 1-34.

Zucca, E. 2008. Extranodal lymphoma: A reappraisal. Annals of Oncology, 19(SUPPL. 4): 77-81. 
